ఠ

\title{
Angiotensin II receptor blockers in the prevention of complications from atrial fibrillation
}

This article was published in the following Dove Press journal:

Vascular Health and Risk Management

10 September 2009

Number of times this article has been viewed

\author{
Gerald V Naccarelli' \\ Frank Peacock ${ }^{2}$ \\ 'Penn State Heart and Vascular \\ Institute, Hershey, Pennsylvania, \\ USA; ${ }^{2}$ Cleveland Clinic, Cleveland, \\ Ohio, USA
}

Correspondence: Gerald V Naccarelli Penn State Heart and Vascular Institute, H407 Derry Township, Hershey,

PA 17033-3907, USA

Tel +7175313907

Fax +7I7 53I 4077

Email gnaccarelli@psu.edu
Abstract: Atrial fibrillation (AF) is the most common form of cardiac arrhythmia and is associated with an increased risk of cardiovascular morbidity and mortality, especially due to ischemic stroke. The occurrence of AF leads to atrial electrical and structural remodeling. The renin-angiotensin system appears to play a role in the development of atrial arrhythmias by its involvement in both of these processes. Large-scale hypertension trials and heart failure trials have indicated the potential value of angiotensin II receptor blockers in the treatment of AF.

Keywords: angiotensin II receptor blockers, atrial fibrillation, cardiac arrhythmia

\section{Introduction}

Atrial fibrillation (AF) is the most common clinically significant cardiac arrhythmia. Overall, it affects $>1 \%$ of the population and is common in the elderly, with a prevalence of almost $10 \%$ in individuals aged over 75 years. ${ }^{1}$ Currently, approximately 2.3 million people in the United States are diagnosed with AF, and this number is expected to rise to 5.6 million by $2050 .^{2-4}$

A 38-year follow-up review of data from the Framingham Study has indicated that men have a 1.5-fold greater risk of developing AF than women and that hypertension and diabetes are significant independent predictors of AF, after adjustment for age and other predisposing conditions. Hypertension was shown to be the most common, independent, and potentially modifiable risk factor for $\mathrm{AF}^{5,6}$ primarily because of its high prevalence in the population. ${ }^{5}$ The cardiac conditions that pose the greatest risk for development of AF include heart failure, myocardial infarction, and valvular heart disease (especially mitral valve disease). In addition, other cardiac conditions that have been associated with the occurrence of AF include myocarditis, hypertrophic cardiomyopathy, congenital heart disease, pericarditis, hypertensive cardiovascular disease, left ventricular hypertrophy, and coronary artery disease. ${ }^{5,7}$ Obesity was not associated with the incidence of AF in the review of Framingham data. ${ }^{5}$ However, it has been proposed as a risk factor for the development of AF in relation to associated left atrial dilation. ${ }^{8}$

The development of AF has been associated with a 1.5- to 1.9-fold greater mortality risk, after adjusting for preexisting cardiovascular conditions, in the original cohort of the Framingham Study. ${ }^{9}$ Much of the morbidity and mortality associated with AF is due to thromboembolic complications resulting in ischemic stroke, especially in the elderly. ${ }^{10}$ Ischemic stroke incidence among patients with nonvalvular AF averages 5\% per year and is approximately 2 to 7 times greater than in individuals without AF. ${ }^{11}$ 
The occurrence of AF leads to atrial electrical and structural remodeling, which both contribute to the maintenance and recurrence of the arrhythmia. ${ }^{12-18}$ Patients who initially present with paroxysmal AF often progress to longer, non-self-terminating bouts, ${ }^{19}$ and enlarged atria are a major risk factor for its recurrence. ${ }^{20,21}$

Current treatment strategies for AF include the prevention of thromboembolism and either rate-control or rhythmcontrol strategies, with pharmacotherapy or left atrial ablation as first- or second-line therapy options, respectively. ${ }^{8}$ These approaches may produce similar outcomes, but rate control may be preferable because agents used to maintain sinus rhythm can have proarrhythmic effects. However, both approaches have important limitations, including proarrhythmic and negative dromotropic effects, respectively. ${ }^{8,22,23}$ In view of this, a preventive strategy may be a more attractive option. ${ }^{7}$ The angiotensin-converting enzyme (ACE) inhibitors have been shown to reduce the incidence of AF postmyocardial infarction and in patients with left ventricular dysfunction. ${ }^{24,25}$ In addition, in recent years, large-scale hypertension trials (Losartan Intervention For Endpoint reduction in hypertension [LIFE] and Valsartan Antihypertensive Long-term Use Evaluation [VALUE]) and heart failure trials (Candesartan in Heart Failure - Assessment of Mortality and Morbidity [CHARM] and Valsartan Heart Failure Trial [Val-HeFT]) have indicated the potential value of angiotensin II receptor blockers (ARBs) in the treatment of $\mathrm{AF}^{26-30}$ The aim of this review is to examine the mechanisms of action and clinical efficacy of ARBs in the prevention of AF.

\section{Preventive mechanisms of ARBs in AF}

The occurrence of uncomplicated AF leads mainly to electrical remodeling due to the high atrial rate (indicated by shortening of refractoriness), whereas structural remodeling develops when AF leads to a hemodynamic burden on the atria. ${ }^{31}$ Cellular electrophysiological studies have indicated that marked reductions occur in the densities of the L-type voltage-gated calcium $\left(\mathrm{Ca}^{2+}\right)$ current, $\mathrm{I}(\mathrm{Ca}, \mathrm{L})$, the transient outward potassium $\left(\mathrm{K}^{+}\right)$current, $\mathrm{I}(\mathrm{TO})$, and the ultra-rapid delayed rectifier $\mathrm{K}^{+}$current, $\mathrm{I}(\mathrm{Kur})$ in atrial myocytes from patients with chronic AF. Similar changes in currents have been noted in myocytes from a canine model of $\mathrm{AF}^{32}$ In both human and canine $\mathrm{AF}$, the reduction in $\mathrm{I}(\mathrm{Ca}, \mathrm{L})$ may explain the observed decrease in action potential duration and effective refractory period that are characteristic electrophysiological features of the remodeled atria. ${ }^{32}$ Thus, it has been suggested that calcium overload and perturbations in calcium handling play prominent roles in AF-induced atrial remodeling in humans. ${ }^{32}$

In addition, angiotensin II exerts its physiologic effects by activating AT1 and AT2 receptor subtypes. Goette et al noted that the occurrence of AF was associated with down regulation of AT1 and upregulation of AT2. ${ }^{33}$ However, recently von Lewinski et al reported data that suggests that the major arrhythmic effects occur secondary to stimulation of the AT1 receptor and thus blockade of the AT1 receptor may be antiarrhythmic. ${ }^{34}$

In contrast, structural remodeling is associated with fibrosis: this is characterized by increased deposition of connective tissue in the atria. The histological substrate of atrial biopsies in patients with lone AF has suggested that the probability of AF increases as the degree of fibrosis increases, and further electrophysiologic modification ultimately leads to self-perpetuation of AF. ${ }^{31,35-39}$

The renin-angiotensin-aldosterone system (RAAS) appears to play a role in the development of arrhythmias by its involvement in both forms of remodeling. For example, angiotensin II has been shown to play a critical role in cardiac remodeling via the promotion of cardiac myocyte hypertrophy and cardiac fibroblast interstitial fibrotic changes associated with left ventricular hypertrophy, postmyocardial infarction remodeling, and congestive heart failure (CHF). ${ }^{40}$ In particular, angiotensin II has been shown to mediate cardiac myocyte hypertrophy directly via induction of immediate early genes through a mitogen-activated protein kinase (MAPK)-dependent pathway. In addition, it has also been shown to mediate cardiac hypertrophy indirectly via stimulation of norepinephrine release from cardiac nerve endings and endothelin from endothelial cells and through multiple effects on cardiac fibroblasts. ${ }^{40-45}$

Electrical remodeling is brought about by the shortening of the atrial effective refractory period (AERP) and of the action potential duration. ${ }^{46-49}$ The inhibitory effects of an ARB (candesartan) and an ACE inhibitor (captopril) on atrial electrical remodeling induced by rapid pacing have been examined in a canine model of $\mathrm{AF}^{50}$ The AERP was measured before, during, and after rapid atrial pacing; infusions of saline, ARB, ACE inhibitor, or angiotensin II were initiated 30 minutes before rapid pacing and continued throughout the study. In the saline and angiotensin II groups, the AERP was significantly shortened during rapid atrial pacing and the rate adaptation of the AERP was lost. In contrast, in the ARB and ACE inhibitor groups, shortening of the AERP after rapid pacing was completely inhibited and the rate adaptation of 
the AERP was preserved, which indicated that endogenous angiotensin II may be involved in the mechanism of atrial electrical remodeling. ${ }^{50}$

In addition to the reduction of blood pressure per se, there are a range of other potential mechanisms by which inhibition of the RAAS may reduce AF (Figure 1). ${ }^{51}$ For example, blockade of the RAAS may prevent left atrial dilatation, atrial fibrosis, dysfunction, and slowing of conduction velocity $44,50,52,53$ and, thus, may be particularly effective in patients with left ventricular dysfunction/heart failure. ${ }^{54}$ Inhibition of the RAAS has also been shown to reduce inflammation and oxidative stress, and to modulate sympathetic nerve activity. ${ }^{55}$ The use of agents that block the RAAS has been shown to increase the efficacy of electrical cardioversion of AF, ${ }^{56-59}$ and some studies have also indicated that blockade of the RAAS by ARBs may have direct antiarrhythmic properties. ${ }^{60,61}$ Thus, inhibition of the RAAS may lead to improvements in the management of AF.

\section{Clinical trials with ARBs in AF}

A range of clinical and experimental studies have shown that the use of ACE inhibitors or ARBs in CHF reduces the occurrence of AF and AF vulnerability via the reduction of atrial structural remodeling and fibrosis. ${ }^{44,53,54,62-66}$

\section{ARBs in patients with heart failure}

A secondary analysis of the results of the CHARM program, which included 7601 patients with symptomatic CHF, has demonstrated that, in addition to significant reductions in cardiovascular deaths and hospital admissions for heart failure with reduced ejection fraction, the ARB candesartan significantly reduced the development of new AF compared with placebo. Moreover, the benefits of treatment with an ARB were accrued regardless of treatment at baseline (which included treatment with ACE inhibitors) and in a wide spectrum of patients with $\mathrm{CHF}$, including those with preserved as well as reduced left ventricular systolic

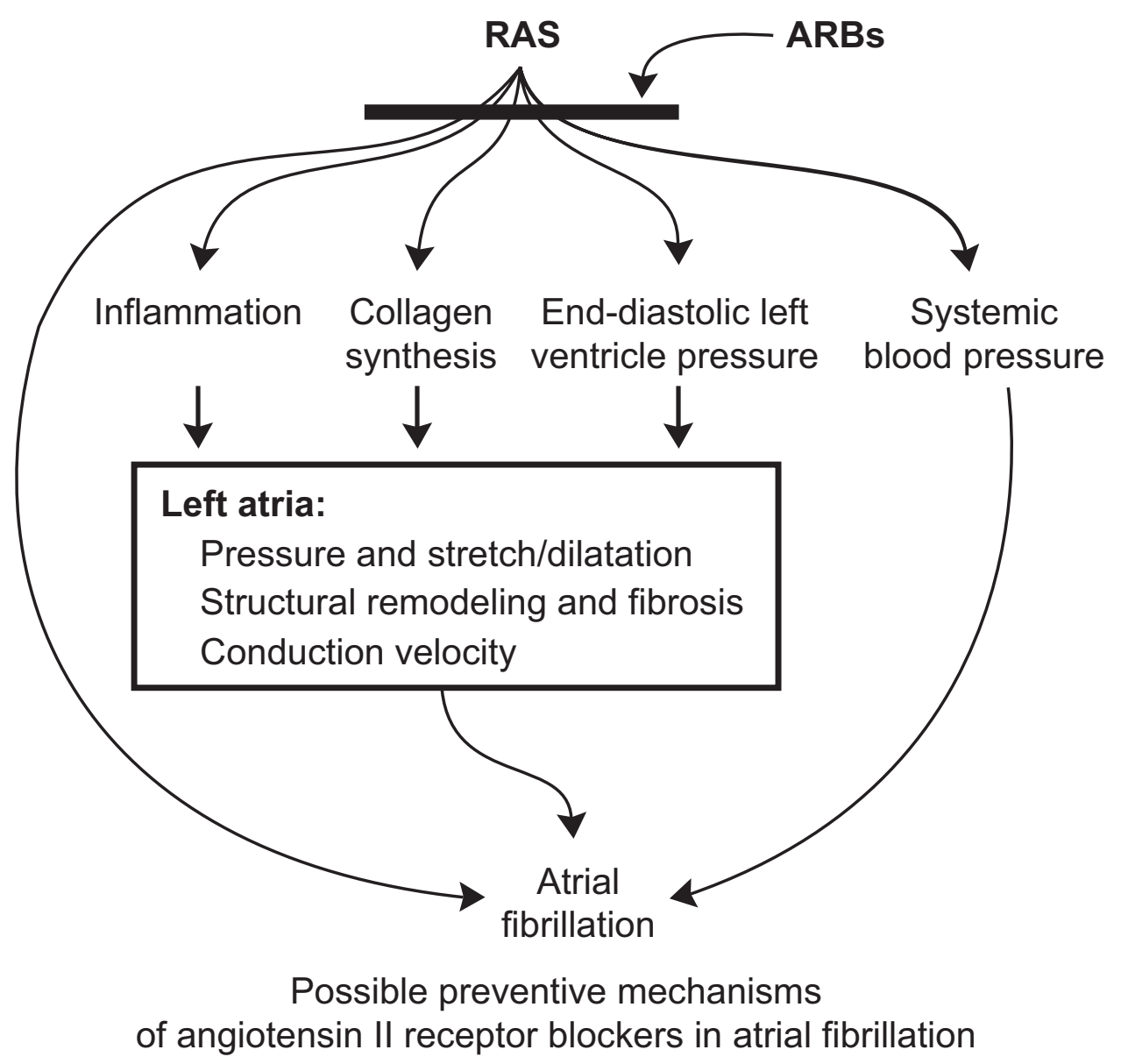

Figure I Possible preventive mechanisms of ARBs in atrial fibrillation. Reproduced with permission from Aksnes T, Flaa A, Strand A, et al. Prevention of new-onset atrial fibrillation and its predictors with angiotensin II receptor blockers in the treatment of hypertension and heart failure.J Hypertens. 2007;25:15-23.51 Copyright @ Wolters Kluwer Health.

Abbreviations: ARBs, angiotensin II receptor blockers; RAS, renin-angiotensin-aldosterone system. 
function (Table 1). ${ }^{67,68}$ In Val-HeFT, the occurrence of AF was associated with worse outcomes and was evaluated on the basis of adverse event reports in patients with heart failure treated with valsartan vs placebo on top of optimal heart failure therapy, which included ACE inhibitors and beta-blockers. ${ }^{69,70}$ Treatment with valsartan significantly reduced the combined endpoint of mortality and morbidity and improved clinical signs and symptoms in patients with heart failure, and also significantly reduced new-onset $\mathrm{AF}$ and reduced the relative risk of developing AF by $37 \%$ compared with placebo, when added to prescribed therapy. However, when ECG recordings from patients with sinus rhythm at enrolment were evaluated at 4, 12, and 24 months and at study end, the presence of at least 1 episode of AF showed no statistically significant difference between valsartan-treated patients and the placebo group (3.9\% and 4.5\%, respectively; $P=0.15$ ) (Table 1). ${ }^{69,70}$

\section{ARBs in the treatment of $A F$ after cardioversion}

The efficacy of treatment with irbesartan in maintaining sinus rhythm after cardioversion has been evaluated in patients with persistent AF. ${ }^{56}$ Patients were divided into 2 groups: group 1 was treated with amiodarone, group 2 with amiodarone plus irbesartan, and both groups underwent electrical cardioversion after 3 weeks of amiodarone administration. All patients started amiodarone after at least 3 weeks of anticoagulation to achieve an international normalized ratio greater than 2 , and the primary endpoint of the study was the length of time to the first recurrence of AF. After 2 months of follow-up, the amiodarone plus irbesartan group had significantly fewer recurrences of AF (63.2\%) than the amiodarone-only group $(84.8 \%$, $P=0.008)$, and had a greater probability of maintaining sinus rhythm $(79.5 \%$ vs $55.9 \%, P=0.007) .{ }^{56}$ There was also a trend toward a lower number of shocks and lower electrical threshold, but this did not reach statistical significance. ${ }^{56}$ Furthermore, in a subsequent study, the combination of irbesartan plus amiodarone decreased the rate of AF recurrence in a dose-dependent manner in lone AF patients. ${ }^{57}$

\section{$A R B s$ in the prevention of new $A F$}

In the Study on Cognition and Prognosis in the Elderly (SCOPE), there was a marked reduction in nonfatal stroke compared with placebo in elderly patients with hypertension who received treatment with an $\mathrm{ARB}$, which may have been due to a reduction in AF (Table 2). ${ }^{71}$

Similarly, the results of the LIFE study indicated that ARB-based treatment produced a $25 \%$ reduction in fatal and nonfatal stroke compared with atenolol-based treatment in hypertensive patients with left ventricular hypertrophy. This was attributable in part to a $45 \%$ lower rate of stroke (24.1 vs 46.5 strokes per 1000 patient-years of follow-up) on $\mathrm{ARB}$ treatment in patients with a history of $\mathrm{AF},{ }^{29}$ but may have also been a reflection of benefits from a reduced incidence of new-onset AF. In a subsequent subanalysis of ECG data from patients without AF by history at baseline, new-onset AF occurred in 150 patients randomized to losartan vs 221 to atenolol (6.8 vs 10.1 per 1000 person-years; relative risk [RR] $0.67, P<0.001)$ despite similar levels of blood pressure reduction (Table 2). ${ }^{28}$ Patients who received losartan tended to stay in sinus rhythm longer (mean, 1809 vs 1709 days from baseline, $P=0.057$ ) than those who received atenolol. Patients with new-onset AF had 2-, 3-, and 5-fold increased rates, respectively, of cardiovascular events, stroke, and hospitalization for heart failure, but there were fewer composite endpoints and strokes in patients who developed new-onset AF in the losartan arm compared to the atenolol treatment arm of the study. ${ }^{28}$

Table I The effects of ARBs on AF and outcomes in clinical trials in patients with left ventricular dysfunction/congestive heart failure

\begin{tabular}{|c|c|c|c|c|}
\hline Study & Design/follow-up & $\mathbf{N}$ & Interventions & AF-related endpoints \\
\hline \multirow[t]{3}{*}{ CHARM $^{67,68}$} & $M C, R, D B, P L$ & 7601 & Candesartan (Can) & Incidence of $\mathrm{AF}$ \\
\hline & Mean, 37.7 months & & PL & $\begin{array}{l}\text { 392/6379 }(6.15 \%) \text { of patients with no AF at baseline } \\
\text { developed AF during follow-up }\end{array}$ \\
\hline & & & & Can $5.55 \%$ vs PL $6.74 \%(O R$ 0.802, $P=0.039)$ \\
\hline \multirow[t]{3}{*}{ Val-HeFT substudy $y^{69,70}$} & $M C, R, D B, P L$ & 4395 & Valsartan (Val) & Incidence of AF \\
\hline & Mean, 23 months & & $\mathrm{PL}$ & $\begin{array}{l}287 / 4395(6.35 \%) \text { of patients with sinus rhythm at } \\
\text { baseline had AF as an adverse event during follow-up }\end{array}$ \\
\hline & & & & Val $5.12 \%$ vs PL $7.95 \%(P=0.0002)$ \\
\hline
\end{tabular}

Note: Trial acronyms are expanded in the text.

Abbreviations: AF, atrial fibrillation; ARB, angiotensin II receptor blocker; DB, double-blind; MC, multicenter; OR, odds ratio; PL, placebo-controlled; R, randomized. 
Table 2 Studies of the effectiveness of ARBs in the prevention of AF (new onset and recurrent)

\begin{tabular}{|c|c|c|c|c|}
\hline Study & Design/follow-up & $\mathbf{N}$ & Interventions & AF-related endpoints \\
\hline \multicolumn{5}{|l|}{ New-onset AF } \\
\hline \multirow[t]{4}{*}{$\mathrm{SCOPE}^{71}$} & MC, R, DB, hypertension & 4964 & Candesartan (Can) & Incidence of nonfatal stroke \\
\hline & (elderly) & & PL & Can 7.4 vs PL $10.3 / 1000$ patient-years \\
\hline & & & & (risk reduction $27.8 \%, P=0.04$ ) \\
\hline & Mean, 3.7 years & & & \\
\hline \multirow[t]{4}{*}{ LIFE $^{28}$} & $\begin{array}{l}\text { MC, R, DB, } \\
\text { hypertension/LVH }\end{array}$ & $885 \mathrm{I}^{\mathrm{a}}$ & Losartan (Los) & Incidence of AF \\
\hline & Mean, 4.8 years & & Atenolol (At) & $\begin{array}{l}\text { Los } 6.8 \text { vs At } 10.1 / 1000 \text { patient-years } \\
\text { (RR } 0.67, P<0.00 I \text { ) }\end{array}$ \\
\hline & & & & Maintenance of sinus rhythm \\
\hline & & & & $\begin{array}{l}\text { Los } 1809 \pm 225 \text { days vs At } 1709 \pm 254 \text { days } \\
(P=0.057)\end{array}$ \\
\hline \multirow[t]{4}{*}{ VALUE $^{27,30}$} & Retrospective analysis & 15,245 & Valsartan (Val) & Incidence of new-onset $\mathrm{AF}$ \\
\hline & of MC, R, DB study & & Amlodipine (Aml) & Val $3.7 \%$ vs Aml $4.3 \%(P=0.044)$ \\
\hline & (hypertension) & & & Rate of persistent $\mathrm{AF}$ \\
\hline & Mean, 4.2 years & & & Val I.4\% vs Aml $2.0 \%(P=0.005)$ \\
\hline \multirow[t]{3}{*}{ ONTARGET ${ }^{72}$} & $M C, R, D B$, patients at & 25,620 & Telmisartan (Tel) & Incidence of new-onset AF \\
\hline & $\begin{array}{l}\text { high risk of vascular } \\
\text { events }\end{array}$ & & Ramipril (Ram) & $\begin{array}{l}\text { Tel } 6.7 \% \text { vs Ram } 6.9 \% \text { vs Ram } \pm \text { Tel } 6.5 \% \\
\text { (all } P=\text { NS between treatments; Tel vs Ram }\end{array}$ \\
\hline & Median, 56 months & & $\begin{array}{l}\text { Ram } \pm \text { Tel } \\
\text { combination therapy }\end{array}$ & RR 0.97) \\
\hline \multicolumn{5}{|l|}{ Recurrent AF } \\
\hline \multirow[t]{3}{*}{ Fogari et $\mathrm{al}^{73}$} & R, open-label, & 296 & Valsartan (Val) & Incidence of recurrent $\mathrm{AF}$ \\
\hline & $\begin{array}{l}\text { hypertension/type } 2 \\
\text { diabetes/AF }\end{array}$ & & Atenolol (At) & $\mathrm{Val} \pm \mathrm{Aml} 20.3 \% \mathrm{vs} A t+\mathrm{Aml} 34.1 \%(P<0.0 \mathrm{l})$ \\
\hline & I year & & $( \pm$ Amlodipine $[$ Aml $]$ ) & \\
\hline \multirow[t]{3}{*}{ Fogari et a $7^{74}$} & $\mathrm{R}, \mathrm{DB}$, hypertension/AF & 369 & Valsartan (Val) & Incidence of recurrent $\mathrm{AF}$ \\
\hline & I year & & Ramipril (Ram) & Val $16.1 \%$ vs Ram $27.9 \%$ vs Aml $47.4 \%$ \\
\hline & & & Amlodipine (Aml) & $(P<0.0 \mathrm{l}$ Val vs Aml and $P<0.05$ Val vs Ram $)$ \\
\hline \multirow[t]{2}{*}{ GISSI-AF ${ }^{75}$} & $M C, R, D B, P L, A F$ & 1442 & Valsartan (V) & Incidence of recurrent AF \\
\hline & Median, I year & & PL & $\begin{array}{l}\text { Val } 5 \mathrm{I} .4 \% \text { vs PL } 52.1 \% \text { (HR 0.99), but trend } \\
\text { favored Val in patients with CHF and/or LV } \\
\text { dysfunction (HR 0.8I) }\end{array}$ \\
\hline \multirow[t]{2}{*}{ CAPRAF $^{76,77}$} & $R, D B, P L, A F$ & 171 & Candesartan (Can) & Incidence of recurrent $\mathrm{AF}$ \\
\hline & 6 months & & PL & $\begin{array}{l}\text { Can } 71 \% \text { vs } P L 65 \%(P=0.20) \text { in patients } \\
\text { with persistent } A F \text { who underwent } E C V\end{array}$ \\
\hline
\end{tabular}

Note: ${ }^{a}$ No AF at baseline.

Abbreviations: AF, atrial fibrillation; ARB, angiotensin II receptor blocker; CHF, congestive heart failure; DB, double-blind; ECV, electrical cardioversion; HR, hazard ratio; $\mathrm{LVH}$, left ventricular hypertrophy; MC, multicenter; PL, placebo; R, randomized; RR, relative risk. Trial acronyms are expanded in the text.

In the VALUE trial, new-onset AF was a secondary prespecified endpoint and ECG recordings were obtained every year and centrally analyzed. During the study, the incidence of at least 1 documented occurrence of new-onset AF was significantly lower in the valsartan treatment group (3.7\%) than in the amlodipine treatment group $(4.3 \%$, odds ratio 0.84) (Table 2). The incidence of persistent $\mathrm{AF}$ was also significantly lower with valsartan than with amlodipine (odds ratio 0.68 , Table 2), and the effects of valsartan on the incidence of $\mathrm{AF}$ remained significant even when potential confounding covariates (age, history of coronary artery disease, left ventricular hypertrophy) were taken into account..$^{27,30}$

In addition, the noninferiority of ARBs compared to ACE inhibitors in the prevention of new-onset AF was demonstrated in the ONTARGET study (Ongoing Telmisartan 
Alone and in Combination With Ramipril Global Endpoint Trial) in patients with vascular disease or high-risk diabetes (Table 2). ${ }^{72}$ In this study, which compared the effectiveness of telmisartan and ramipril in reducing cardiovascular death, myocardial infarction, stroke, and hospitalization for heart failure in patients at risk, the diagnosis of new-onset AF was a secondary endpoint. ${ }^{72}$ Telmisartan treatment produced a greater reduction in blood pressure than ramipril and, after a median follow-up of 56 months, the primary outcome of death from cardiovascular causes, myocardial infarction, stroke, or hospitalization for heart failure had occurred in 1412 patients in the ramipril group (16.5\%) vs 1423 patients in the telmisartan group (16.7\%, RR 1.01). However, the combination of the 2 drugs was associated with a greater frequency of adverse events without an increase in benefit. ${ }^{72}$

\section{$A R B s$ in the prevention of recurrent $A F$}

Patients with hypertension and type 2 diabetes have an elevated risk of cardiovascular events and typically require combination antihypertensive therapy to achieve goal blood pressure levels. In view of this, Fogari et al ${ }^{73}$ compared the effectiveness of valsartan + amlodipine and atenolol + amlodipine combinations on the prevention of AF recurrence in hypertensive patients with well-controlled type 2 diabetes in sinus rhythm who had at least 2 ECG-documented episodes of AF in the previous 6 months. Significantly fewer patients who were followed up for 1 year had recurrent AF with an ARB in addition to antiarrhythmic agents than with atenolol (Table 2). ${ }^{73}$ Overall, despite similar levels of blood pressure reduction, the valsartan + amlodipine combination was more effective in preventing AF in patients treated with amiodarone or propafenone. ${ }^{73}$ In addition, ARB therapy with valsartan led to significantly fewer recurrences of AF after 12 weeks of treatment than amlodipine, and significantly less recurrence than both amlodipine and ramipril after 1 year in patients with mild hypertension and a history of AF (Table 2). ${ }^{74}$ Although blood pressure lowering could be a beneficial mechanism of action for the reduction of AF with both types of RAAS inhibitors, there were no statistically significant differences in blood pressure between the 3 treatment groups in this study. This suggested that both ARBs and ACE inhibitors may exert an antiarrhythmic effect beyond their effects on blood pressure. ${ }^{74}$ However, no statistically significant reduction in the recurrence of AF was noted with valsartan treatment compared with placebo in the recent GISSI-AF study (Gruppo Italiano per lo Studio della Sopravvivenza nell'Infarto Miocardico: Use of Valsartan and Angiotensin II AT1-Receptor Blocker in the Prevention of
Atrial Fibrillation Recurrence). ${ }^{75}$ This may have been due to issues relating to the study design, broad selection criteria, and/or the patients' relatively low-risk clinical conditions (and possible consequent low level of RAAS activation), and optimized background therapy. Moreover, the use of candesartan had no influence on echocardiographic variables or on the recurrence rate of AF after cardioversion in the 6-month Candesartan in the Prevention of Relapsing Atrial Fibrillation (CAPRAF) study. ${ }^{76,77}$

\section{Ongoing trials of $A R B s$ in $A F$}

It is hoped that a range of ongoing and planned future studies will help to clarify the possible beneficial effects of treatment with ARBs in terms of prevention of AF complications and prevention of AF recurrence (Table 3). The Atrial Fibrillation Clopidogrel Trial with Irbesartan for Prevention of Vascular Events (ACTIVE I) trial will randomize 9000 patients with a history of AF to receive irbesartan or placebo with a planned mean follow-up of 3 years. ACTIVE I is part of the ACTIVE trial program investigating the effect of irbesartan on the occurrence of stroke, myocardial infarction or vascular death, hospitalization for heart failure (primary endpoints) and recurrence of AF, development of cardiac structural remodeling, microalbuminuria, cognitive function, and quality of life (secondary endpoints). ${ }^{78}$ In addition, the Angiotensin II Antagonist in Paroxysmal Atrial Fibrillation (ANTIPAF) trial will compare the effect of olmesartan and placebo in patients with paroxysmal $\mathrm{AF}^{79}$ and the aim of the planned I-PACE trial is to investigate the effects of irbesartan in hypertensive patients with pacemakers who have recurrent atrial high-rate episodes (Irbesartan for the Prevention of Atrial Arrhythmias and Cardiac Electrical Remodeling in Patients With Hypertension and Permanent Pacemakers). ${ }^{80}$

\section{Conclusions and clinical recommendations}

The prevention of AF is particularly challenging because of its high incidence. ${ }^{1,3,81}$ Because ARBs block the actions of angiotensin II, it seems likely that they interfere with structural and electrical remodeling and consequently provide benefits in terms of prevention of new-onset $A F$ and recurrence of AF. So far, the body of evidence supports that ARBs may be useful in combination with other antiarrhythmic agents and not as sole antiarrhythmic therapy in suppressing AF recurrences. However, while the possibility of hemodynamic benefits and direct antiarrhythmic effects cannot be excluded, it is hoped that the results of ongoing prospective studies, such as ACTIVE I and I-PACE, will clarify 
Table 3 Summary of ongoing prospective trials of ARBs in patients with AF

\begin{tabular}{|c|c|c|c|c|}
\hline Study & Design/follow-up & $\mathbf{N}$ & Interventions & AF-related endpoints \\
\hline ACTIVE I8 & $\begin{array}{l}\text { Partial factorial, DB, PL,AF } \\
\text { Mean, } 3 \text { years }\end{array}$ & 9000 & $\begin{array}{l}\text { Irbesartan (Irb) } \\
\mathrm{PL} \\
\text { Open clopidogrel plus ASA } \\
\text { or oral anticoagulation }\end{array}$ & Incidence of recurrent $\mathrm{AF}$ \\
\hline ANTIPAF ${ }^{79}$ & $\begin{array}{l}\text { MC, R, DB, PL, AF } \\
\text { I year }\end{array}$ & $422^{\mathrm{a}}$ & $\begin{array}{l}\text { Olmesartan (OI) } \\
\text { PL }\end{array}$ & $\begin{array}{l}\text { Incidence of pAF } \\
\text { (Percentage of days with documented } \\
\text { episodes of pAF on daily transtelephonic } \\
\text { tele-ECG recordings) }\end{array}$ \\
\hline I-PACE ${ }^{80}$ & $\begin{array}{l}\text { MC, R, DB, PL, hypertensive } \\
\text { patients with permanent } \\
\text { pacemakers and risk factors } \\
\text { for developing AF }\end{array}$ & 200 & $\begin{array}{l}\text { Irbesartan (Irb) } \\
\text { PL }\end{array}$ & Time to recurrent AHRE \\
\hline
\end{tabular}

Note: aPatients stratified according to beta-blocker use.

Abbreviations: AF, atrial fibrillation; ARB, angiotensin II receptor blocker; AHRE, atrial high-rate episodes; ASA, aspirin; DB, double-blind; ECG, electrocardiograph; MC, multicenter; PAF, paroxysmal AF; PL, placebo; R, randomized.

the benefits of ARB treatment in relation to AF. Although valsartan was ineffective in suppressing AF in GISSI-AF, this study and the results of ACTIVE I may be limited by the high percentage of patients who had background ACE inhibitor therapy. The results of ACTIVE I may support the use of ARBs related to meaningful endpoints and not surrogates such as AF recurrence. Although it is not currently possible to specifically recommend the use of ARBs for prevention of AF in routine clinical practice, ARBs are well tolerated and may be considered for use in patients with AF and coexisting clinical conditions such as hypertension, coronary heart disease, CHF, and type 2 diabetes.

\section{Acknowledgments and financial disclosure}

This study was supported by the Bristol-Myers Squibb/ Sanofi-Synthelabo Partnership. All authors contributed to the interpretation of data, its development, and the approval of the final manuscript. The authors received no financial support or other compensation related to its development. The authors thank Pam Milner and Stephanie Eide who provided editorial services on behalf of Bristol-Myers Squibb and sanofi-aventis.

\section{References}

1. Phillips SJ, Whisnant JP, O'Fallon WM, Frye RL. Prevalence of cardiovascular disease and diabetes mellitus in residents of Rochester, Minnesota. Mayo Clin Proc. 1990;65(3):344-359.

2. Go AS, Hylek EM, Phillips KA, et al. Prevalence of diagnosed atrial fibrillation in adults: national implications for rhythm management and stroke prevention: the AnTicoagulation and Risk Factors in Atrial Fibrillation (ATRIA) Study. JAMA. 2001;285(18):2370-2375.

3. Kannel WB, Benjamin EJ. Status of the epidemiology of atrial fibrillation. Med Clin North Am. 2008;92(1):17-40, ix.
4. Miyasaka Y, Barnes ME, Gersh BJ, et al. Secular trends in incidence of atrial fibrillation in Olmsted County, Minnesota, 1980 to 2000, and implications on the projections for future prevalence. Circulation. 2006;114(2):119-125.

5. Kannel WB, Wolf PA, Benjamin EJ, Levy D. Prevalence, incidence, prognosis, and predisposing conditions for atrial fibrillation: populationbased estimates. Am J Cardiol. 1998;82(8A):2N-9N.

6. Psaty BM, Manolio TA, Kuller LH, et al. Incidence of and risk factors for atrial fibrillation in older adults. Circulation. 1997;96(7):2455-2461.

7. Novo G, Guttilla D, Fazio G, Cooper D, Novo S. The role of the reninangiotensin system in atrial fibrillation and the therapeutic effects of ACE-Is and ARBS. Br J Clin Pharmacol. 2008;66(3):345-351.

8. Fuster V, Ryden LE, Cannom DS, et al. ACC/AHA/ESC 2006 guidelines for the management of patients with atrial fibrillation-executive summary: a report of the American College of Cardiology/American Heart Association Task Force on Practice Guidelines and the European Society of Cardiology Committee for Practice Guidelines (Writing Committee to Revise the 2001 Guidelines for the Management of Patients with Atrial Fibrillation). Eur Heart J. 2006;27(16):1979-2030.

9. Benjamin EJ, Wolf PA, D’Agostino RB, Silbershatz H, Kannel WB, Levy D. Impact of atrial fibrillation on the risk of death: the Framingham Heart Study. Circulation. 1998;98(10):946-952.

10. Hart RG, Halperin JL. Atrial fibrillation and stroke: concepts and controversies. Stroke. 2001;32(3):803-808.

11. Wolf PA, Abbott RD, Kannel WB. Atrial fibrillation as an independent risk factor for stroke: the Framingham Study. Stroke. 1991;22(8): 983-988.

12. Allessie MA. Atrial electrophysiologic remodeling: another vicious circle? J Cardiovasc Electrophysiol. 1998;9(12):1378-1393.

13. Ausma J, van der Velden HM, Lenders MH, et al. Reverse structural and gap-junctional remodeling after prolonged atrial fibrillation in the goat. Circulation. 2003;107(15):2051-2058.

14. Heidbuchel H. A paradigm shift in treatment for atrial fibrillation: from electrical to structural therapy? Eur Heart J. 2003;24(23): 2077-2078.

15. Hobbs WJ, Fynn S, Todd DM, Wolfson P, Galloway M, Garratt CJ. Reversal of atrial electrical remodeling after cardioversion of persistent atrial fibrillation in humans. Circulation. 2000;101(10):1145-1151.

16. Nattel S, Shiroshita-Takeshita A, Cardin S, Pelletier P. Mechanisms of atrial remodeling and clinical relevance. Curr Opin Cardiol. 2005;20(1):21-25.

17. Sanfilippo AJ, Abascal VM, Sheehan M, et al. Atrial enlargement as a consequence of atrial fibrillation. A prospective echocardiographic study. Circulation. 1990;82(3):792-797. 
18. Thijssen VL, Ausma J, Liu GS, Allessie MA, van Eys GJ, Borgers M. Structural changes of atrial myocardium during chronic atrial fibrillation. Cardiovasc Pathol. 2000;9(1):17-28.

19. Allessie MA, Boyden PA, Camm AJ, et al. Pathophysiology and prevention of atrial fibrillation. Circulation. 2001;103(5):769-777.

20. Mattioli AV, Vivoli D, Bastia E. Doppler echocardiographic parameters predictive of recurrence of atrial fibrillation of different etiologic origins. J Ultrasound Med. 1997;16(10):695-698.

21. Verdecchia P, Reboldi G, Gattobigio R, et al. Atrial fibrillation in hypertension: predictors and outcome. Hypertension. 2003;41(2):218-223.

22. Freudenberger RS, Wilson AC, Kostis JB. Comparison of rate versus rhythm control for atrial fibrillation in patients with left ventricular dysfunction (from the AFFIRM Study). Am J Cardiol. 2007;100(2):247-252.

23. Hohnloser SH, Kuck KH, Lilienthal J. Rhythm or rate control in atrial fibrillation - Pharmacological Intervention in Atrial Fibrillation (PIAF): a randomised trial. Lancet. 2000;356(9244):1789-1794.

24. Pedersen OD, Bagger H, Kober L, Torp-Pedersen C. Trandolapril reduces the incidence of atrial fibrillation after acute myocardial infarction in patients with left ventricular dysfunction. Circulation. 1999;100(4):376-380.

25. Vermes E, Tardif JC, Bourassa MG, et al. Enalapril decreases the incidence of atrial fibrillation in patients with left ventricular dysfunction: insight from the Studies Of Left Ventricular Dysfunction (SOLVD) trials. Circulation. 2003;107(23):2926-2931.

26. Maggioni AP, Latini R, Carson PE, et al. Valsartan reduces the incidence of atrial fibrillation in patients with heart failure: results from the Valsartan Heart Failure Trial (Val-HeFT). Am Heart J. 2005;149(3):548-557.

27. Schmieder RE, Kjeldsen SE, Julius S, McInnes GT, Zanchetti A, Hua TA. Reduced incidence of new-onset atrial fibrillation with angiotensin II receptor blockade: the VALUE trial. $J$ Hypertens. 2008;26(3):403-411.

28. Wachtell K, Lehto M, Gerdts E, et al. Angiotensin II receptor blockade reduces new-onset atrial fibrillation and subsequent stroke compared to atenolol: the Losartan Intervention For End Point Reduction in Hypertension (LIFE) study. J Am Coll Cardiol. 2005;45(5): $712-719$.

29. Wachtell K, Hornestam B, Lehto M, et al. Cardiovascular morbidity and mortality in hypertensive patients with a history of atrial fibrillation: The Losartan Intervention For End Point Reduction in Hypertension (LIFE) study. J Am Coll Cardiol. 2005;45(5):705-711.

30. Weber MA, Julius S, Kjeldsen SE, et al. Blood pressure dependent and independent effects of antihypertensive treatment on clinical events in the VALUE Trial. Lancet. 2004;363(9426):2049-2051.

31. Schoonderwoerd BA, Van Gelder IC, Van Veldhuisen DJ, Van Den Berg MP, Crijns HJ. Electrical and structural remodeling: role in the genesis and maintenance of atrial fibrillation. Prog Cardiovasc Dis. 2005;48(3):153-168.

32. Van Wagoner DR, Nerbonne JM. Molecular basis of electrical remodeling in atrial fibrillation. J Mol Cell Cardiol. 2000;32(6):1101-1117.

33. Goette A, Arndt M, Rocken C, et al. Regulation of angiotensin II receptor subtypes during atrial fibrillation in humans. Circulation. 2000;101(23):2678-2681.

34. von Lewinski D, Kockskamper J, Rubertus SU, et al. Direct proarrhythmogenic effects of angiotensin II can be suppressed by AT1 receptor blockade in human atrial myocardium. Eur J Heart Fail. 2008;10(12):1172-1176.

35. Cha YM, Redfield MM, Shen WK, Gersh BJ. Atrial fibrillation and ventricular dysfunction: a vicious electromechanical cycle. Circulation. 2004;109(23):2839-2843.

36. Frustaci A, Chimenti C, Bellocci F, Morgante E, Russo MA, Maseri A. Histological substrate of atrial biopsies in patients with lone atrial fibrillation. Circulation. 1997;96(4):1180-1184.

37. Van Gelder IC, Hemels ME. The progressive nature of atrial fibrillation: a rationale for early restoration and maintenance of sinus rhythm. Europace. 2006;8(11):943-949.
38. Verheule S, Wilson E, Everett T, Shanbhag S, Golden C, Olgin J. Alterations in atrial electrophysiology and tissue structure in a canine model of chronic atrial dilatation due to mitral regurgitation. Circulation. 2003;107(20):2615-2622.

39. Wijffels MC, Kirchhof CJ, Dorland R, Allessie MA. Atrial fibrillation begets atrial fibrillation. A study in awake chronically instrumented goats. Circulation. 1995;92(7):1954-1968.

40. Schnee JM, Hsueh WA. Angiotensin II, adhesion, and cardiac fibrosis. Cardiovasc Res. 2000;46(2):264-268.

41. Brilla CG, Zhou G, Matsubara L, Weber KT. Collagen metabolism in cultured adult rat cardiac fibroblasts: response to angiotensin II and aldosterone. J Mol Cell Cardiol. 1994;26(7):809-820.

42. Goette A, Staack T, Rocken C, et al. Increased expression of extracellular signal-regulated kinase and angiotensin-converting enzyme in human atria during atrial fibrillation. J Am Coll Cardiol. 2000;35(6): 1669-1677.

43. Li D, Fareh S, Leung TK, Nattel S. Promotion of atrial fibrillation by heart failure in dogs: atrial remodeling of a different sort. Circulation. 1999;100(1):87-95.

44. Li D, Shinagawa K, Pang L, et al. Effects of angiotensin-converting enzyme inhibition on the development of the atrial fibrillation substrate in dogs with ventricular tachypacing-induced congestive heart failure. Circulation. 2001;104(21):2608-2614.

45. Sadoshima J, Izumo S. Molecular characterization of angiotensin II induced hypertrophy of cardiac myocytes and hyperplasia of cardiac fibroblasts. Critical role of the AT1 receptor subtype. Circ Res. 1993;73(3): 413-423.

46. Bosch RF, Zeng X, Grammer JB, Popovic K, Mewis C, Kuhlkamp V. Ionic mechanisms of electrical remodeling in human atrial fibrillation. Cardiovasc Res. 1999;44(1):121-131.

47. Bosch RF, Nattel S. Cellular electrophysiology of atrial fibrillation. Cardiovasc Res. 2002;54(2):259-269.

48. Yu WC, Lee SH, Tai CT, et al. Reversal of atrial electrical remodeling following cardioversion of long-standing atrial fibrillation in man. Cardiovasc Res. 1999;42(2):470-476.

49. Yue L, Feng J, Gaspo R, Li GR, Wang Z, Nattel S. Ionic remodeling underlying action potential changes in a canine model of atrial fibrillation. Circ Res. 1997;81(4):512-525.

50. Nakashima H, Kumagai K, Urata H, Gondo N, Ideishi M, Arakawa K. Angiotensin II antagonist prevents electrical remodeling in atrial fibrillation. Circulation. 2000;101(22):2612-2617.

51. Aksnes TA, Flaa A, Strand A, Kjeldsen SE. Prevention of new-onset atrial fibrillation and its predictors with angiotensin II-receptor blockers in the treatment of hypertension and heart failure. J Hypertens. 2007;25(1):15-23.

52. Shi Y, Ducharme A, Li D, Gaspo R, Nattel S, Tardif JC. Remodeling of atrial dimensions and emptying function in canine models of atrial fibrillation. Cardiovasc Res. 2001;52(2):217-225.

53. Shi Y, Li D, Tardif JC, Nattel S. Enalapril effects on atrial remodeling and atrial fibrillation in experimental congestive heart failure. Cardiovasc Res. 2002;54(2):456-461.

54. Healey JS, Baranchuk A, Crystal E, et al. Prevention of atrial fibrillation with angiotensin-converting enzyme inhibitors and angiotensin receptor blockers: a meta-analysis. J Am Coll Cardiol. 2005;45(11):1832-1839.

55. Murray KT, Mace LC, Yang Z. Nonantiarrhythmic drug therapy for atrial fibrillation. Heart Rhythm. 2007;4(3 Suppl):S88-S90.

56. Madrid AH, Bueno MG, Rebollo JM, et al. Use of irbesartan to maintain sinus rhythm in patients with long-lasting persistent atrial fibrillation: a prospective and randomized study. Circulation. 2002;106(3):331-336.

57. Madrid AH, Marin IM, Cervantes CE, et al. Prevention of recurrences in patients with lone atrial fibrillation. The dose-dependent effect of angiotensin II receptor blockers. J Renin Angiotensin Aldosterone Syst. 2004;5(3):114-120

58. Van Noord T, Crijns HJ, Van Den Berg MP, Van Veldhuisen DJ, Van Gelder IC. Pretreatment with ACE inhibitors improves acute outcome of electrical cardioversion in patients with persistent atrial fibrillation. BMC Cardiovasc Disord. 2005;5(1):3. 
59. Zaman AG, Kearney MT, Schecter C, Worthley SG, Nolan J. Angiotensin-converting enzyme inhibitors as adjunctive therapy in patients with persistent atrial fibrillation. Am Heart J. 2004;147(5): 823-827.

60. Caballero R, Delpon E, Valenzuela C, Longobardo M, Tamargo J. Losartan and its metabolite E3174 modify cardiac delayed rectifier K(+) currents. Circulation. 2000;101(10):1199-1205.

61. Moreno I, Caballero R, Gonzalez T, et al. Effects of irbesartan on cloned potassium channels involved in human cardiac repolarization. J Pharmacol Exp Ther. 2003;304(2):862-873.

62. Boldt A, Scholl A, Garbade J, et al. ACE-inhibitor treatment attenuates atrial structural remodeling in patients with lone chronic atrial fibrillation. Basic Res Cardiol. 2006;101(3):261-267.

63. Kumagai K, Nakashima H, Urata H, Gondo N, Arakawa K, Saku K. Effects of angiotensin II type 1 receptor antagonist on electrical and structural remodeling in atrial fibrillation. J Am Coll Cardiol. 2003;41(12):2197-2204.

64. Li Y, Li W, Yang B, et al. Effects of Cilazapril on atrial electrical, structural and functional remodeling in atrial fibrillation dogs. J Electrocardiol. 2007;40(1):100-106

65. Okazaki H, Minamino T, Tsukamoto O, et al. Angiotensin II type 1 receptor blocker prevents atrial structural remodeling in rats with hypertension induced by chronic nitric oxide inhibition. Hypertens Res. 2006;29(4):277-284.

66. Sakabe M, Fujiki A, Nishida K, et al. Enalapril prevents perpetuation of atrial fibrillation by suppressing atrial fibrosis and over-expression of connexin 43 in a canine model of atrial pacing-induced left ventricular dysfunction. J Cardiovasc Pharmacol. 2004;43(6):851-859.

67. Ducharme A, Swedberg K, Pfeffer MA, et al. Prevention of atrial fibrillation in patients with symptomatic chronic heart failure by candesartan in the Candesartan in Heart failure: Assessment of Reduction in Mortality and morbidity (CHARM) program. Am Heart J. 2006;152(1):86-92.

68. Pfeffer MA, Swedberg K, Granger CB, et al. Effects of candesartan on mortality and morbidity in patients with chronic heart failure: the CHARM-Overall programme. Lancet. 2003;362(9386):759-766.

69. Cohn JN, Tognoni G. A randomized trial of the angiotensinreceptor blocker valsartan in chronic heart failure. $N \mathrm{Engl} \mathrm{J} \mathrm{Med.}$ 2001;345(23):1667-1675.

70. Maggioni AP, Latini R, Carson PE, et al. Valsartan reduces the incidence of atrial fibrillation in patients with heart failure: results from the Valsartan Heart Failure Trial (Val-HeFT). Am Heart J. 2005;149(3):548-557.
71. Lithell H, Hansson L, Skoog I, et al. The Study of Cognition and Prognosis in the Elderley (SCOPE): principal results of a randomized double-blind intervention trial. J Hypertens. 2003;21(5):875-886.

72. ONTARGET Investigators, Yusuf S, Teo KK, et al. Telmisartan, ramipril, or both in patients at high risk for vascular events. $N$ Engl $J$ Med. 2008;358(15):1547-1559.

73. Fogari R, Zoppi A, Mugellini A, et al. Comparative evaluation of effect of valsartan/amlodipine and atenolol/amlodipine combinations on atrial fibrillation recurrence in hypertensive patients with type 2 diabetes mellitus. J Cardiovasc Pharmacol. 2008;51(3):217-222.

74. Fogari R, Derosa G, Ferrari I, et al. Effect of valsartan and ramipril on atrial fibrillation recurrence and $\mathrm{P}$-wave dispersion in hypertensive patients with recurrent symptomatic lone atrial fibrillation. Am J Hypertens. 2008;21(9):1034-1039.

75. GISSI-AF Investigators, Disertori M, atini R, et al. Valsartan for prevention of recurrent atrial fibrillation. $N$ Engl J Med. 2009;360(16): $1606-1617$.

76. Grundvold I, Tveit A, Smith P, Seljeflot I, Abdelnoor M, Arnesen H. The predictive value of transthoracic echocardiographic variables for sinus rhythm maintenance after electrical cardioversion of atrial fibrillation. Results from the CAPRAF study, a prospective, randomized, placebocontrolled study. Cardiology. 2008;111(1):30-35.

77. Tveit A, Grundvold I, Olufsen M, et al. Candesartan in the prevention of relapsing atrial fibrillation. Int J Cardiol. 2007;120(1):85-91.

78. Active Steering Committee, ACTIVE Investigators, Connolly S, et al. Rationale and design of ACTIVE: the atrial fibrillation clopidogrel trial with irbesartan for prevention of vascular events. Am Heart J. 2006;151(6):1187-1193.

79. Goette A, Breithardt G, Fetsch T, et al. Angiotensin II antagonist in paroxysmal atrial fibrillation (ANTIPAF) trial: rationale and study design. Clin Drug Investig. 2007;27(10):697-705.

80. Irbesartan for the Prevention of Atrial Arrhythmias and Cardiac Electrical Remodeling in Patients With Hypertension and Permanent Pacemakers (NCT00225667). [ClinicalTrials.gov Web site]. http:// www.clinicaltrials.gov/ct2/show/NCT00225667?term=NCT0022566 7\&rank=1. Accessed June 28, 2009.

81. Go AS, Hylek EM, Phillips KA, et al. Prevalence of diagnosed atrial fibrillation in adults: national implications for rhythm management and stroke prevention: the AnTicoagulation and Risk Factors in Atrial Fibrillation (ATRIA) Study. JAMA. 2001;285(18):2370-2375.
Vascular Health and Risk Management

\section{Publish your work in this journal}

Vascular Health and Risk Management is an international, peerreviewed journal of therapeutics and risk management, focusing on concise rapid reporting of clinical studies on the processes involved in the maintenance of vascular health; the monitoring, prevention and treatment of vascular disease and its sequelae; and the involvement of

\section{Dovepress}

metabolic disorders, particularly diabetes. This journal is indexed on PubMed Central and MedLine. The manuscript management system is completely online and includes a very quick and fair peer-review system, which is all easy to use. Visit http://www.dovepress.com/ testimonials.php to read real quotes from published authors. 